\title{
Mine waste: Consolidation behaviour of precious metal tailings
}

Monica Figueroa ${ }^{1}$, Ahlam Abdulnabi ${ }^{1}$, Nicholas Beier ${ }^{1}$

${ }^{1}$ Department of Civil Engineering, University of Alberta

\begin{abstract}
All mine processing plants generate waste. These byproducts include waste rock and a finegrained slurry referred to as 'tailings'. The primary objective of treating tailings is to remove water, to enhance strength and stiffness. Studying the geotechnical properties of tailings is essential to understand consolidation behaviour and facilitate land reclamation. Moreover, the geochemical characteristics of tailings should be examined to examine the potential onset of acid rock drainage (ARD). Acid rock drainage occurs when $\mathrm{pH}$ falls below 4, which can cause metal heavy leaching as they become present in solution. This study investigates both the geotechnical and geochemical behaviour of precious metal tailings in atmospheric conditions. The geochemical parameters of interest are $\mathrm{pH}$, redox potential (Eh) and electric conductivity (Ec). The Large Strain Consolidation test (LSC) was implemented to characterize the compressibility behaviour of the sample. Accordingly, the amount of deformation that the tailings underwent was measured as they were loaded to different effective stresses. In addition, the hydraulic conductivity or the velocity of water flow was measured at the end of each consolidation step. Furthermore, the chemical parameters were evaluated using standardized probes. The tailings exhibit high compressibility during self-weight consolidation due to a combination of high initial void ratio and a high initial saturated hydraulic conductivity. In addition, hydraulic conductivity decreases nonlinearly as the samples are loaded because loading reduces the pore volume. The permeability decreased two orders of magnitude during loading, from $2.14^{*} 10^{-05} \mathrm{~m} / \mathrm{s}$ to $1.60^{*} 10^{-7} \mathrm{~m} / \mathrm{s}$. From the geochemical point of view, there is no significant change in $\mathrm{pH}$ as the tailings consolidate. In this scenario, the presence of calcium carbonate has an acid-neutralizing capacity. Moreover, there is a slight increase in both redox potential and electric conductivity due to exposure to the atmosphere. The increasing trend of redox potential had a slope of $10 \mathrm{mV}$ per day. While the slope of electric conductivity was $9 \mathrm{mS} /$ $\mathrm{cm}$ per day.
\end{abstract}

Key words:

precious metal tailings, compressibility, saturated hydraulic conductivity, geochemical tests

Cite as: Figueroa M., Abdulnabi A., and Beier N. 2019. Consolidation behaviour of precious metal tailings. Alberta Academic Review, Vol 2 (2) 29-30, WISEST Special Issue (not peerreviewed), DOI 10.29173/aar41. 
Figueroa et al., 2019

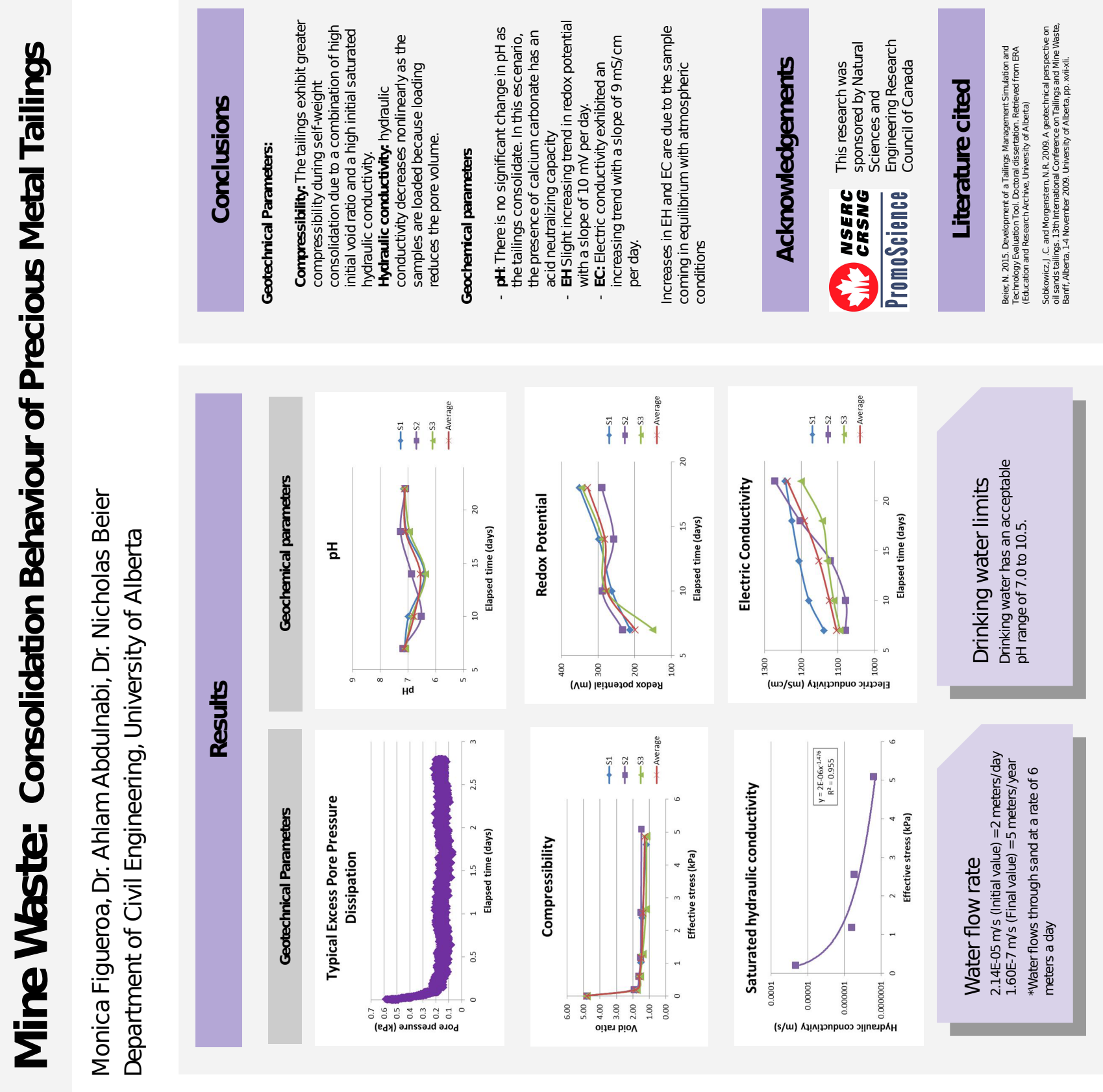

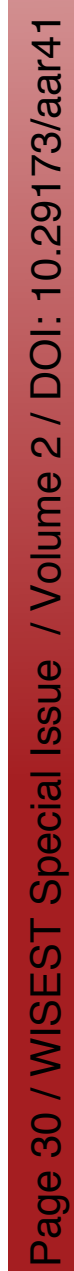
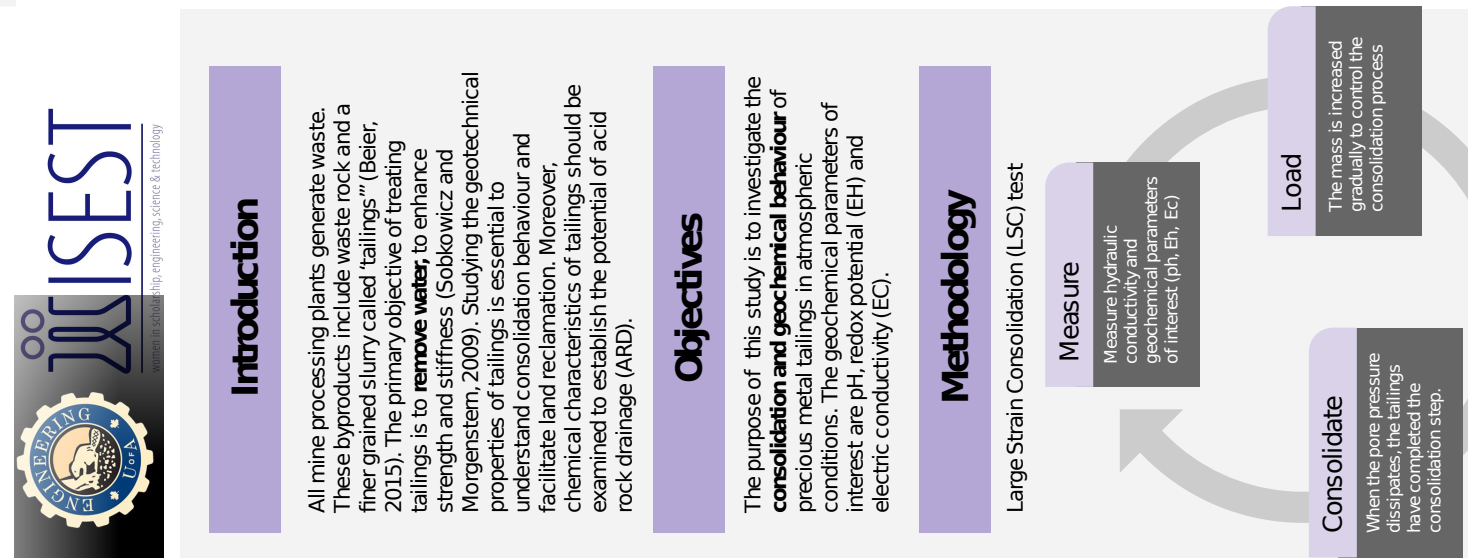